\title{
Functions and Main Directions of Development of the Integrated Educational-Industrial Complex "College_University-Enterprise"
}

\author{
Albina R. Shaidullina ${ }^{1}$, Oleg V. Sinitzyn ${ }^{2}$, Alsu R. Nabiyeva ${ }^{3}$, Sergey A. Yakovlev ${ }^{4}$, Ilya N. Maksimov², Albina \\ R. Gatina ${ }^{5}$ \& Linar G. Akhmetov ${ }^{2}$ \\ ${ }^{1}$ Almetyevsk State Oil Institute, Almetyevsk, Russia \\ ${ }^{2}$ Kazan (Volga region) Federal University, Kazan, Russia \\ ${ }^{3}$ Kazan Cooperative Institute (Branch) of the Russian University of Cooperation, Kazan, Russia \\ ${ }^{4}$ Ulyanovsk State Agricultural Academy named after P. A. Stolypin, Ulyanovsk, Russia \\ ${ }^{5}$ Naberezhnye Chelny Institute of Social-Pedagogical Technologies and Resources, Naberezhnye Chelny, \\ Russia
}

Correspondence: Albina R. Shaidullina, Foreign Languages' Department, Almetyevsk State Oil Institute, Almetyevsk, 423450, Russia. E-mail: albina-plus@mail.ru

Received: December 29, 2014

doi:10.5539/res.v7n4p228

\author{
Accepted: January 22, 2015 Online Published: February 11, 2015 \\ URL: http://dx.doi.org/10.5539/res.v7n4p228
}

\begin{abstract}
Structural and functional stability of college, university and industry integration in regional system of professional education is achieved through the creation of common educational-industrial space. The leading approach to the study of this problem is an integrative approach which allows predicting the transition of the integrated system "college - university - enterprise" on the qualitatively new level due to the agreed goals, tasks, functions, and actions of this system subjects, contributing to the implementation of forward-looking professional training of competitive specialists. The main functions of the development of the integrated educational-industrial complex "college-university-enterprise" in the article are indicated as follows: coordinating, prognostic, anticipatory, consolidating, corporate, sublimating. The article submissions represent a theoretical value to researchers concerned with integration issues, and also have practical significance for subjects of the integrated system of "education-production" in order to prepare specialists meeting the requirements of modern production.
\end{abstract}

Keywords: integration, functions, directions, integrated educational-industrial complex, college, university, enterprise

\section{Introduction}

Russian pedagogical and psychological school of personality-oriented learning is a recognized leader in the world. Nominally teaching for many decades is personality-oriented, and the student is considered as an active member of the educational process. Central core is the learner-An active member of the educational process, realizing his/her right to receive professional training in accordance with his/her needs, abilities and capabilities, has the right to participate in managing the education and the right to receive a qualitative professional education at any stage of professional activities.

The main idea of this article is the organic nature of interpenetrating functions of subjects of the integrated system "college- university - production" conducive to the organization of vocational training, which is built at the junction of sectorial production requirements and educational standards, allowing for more efficiency and effectiveness of education by eliminating the duplication of its content, while maintaining fundamental, practical and problem orientating (Shaidullina, 2014; Shaidullina, 2015). Such training is anticipatory, it is based on the best professional broadcasting of professional experience and outfitting students with an individual program of professional self-realization, contributing to the gradual formation of adaptive abilities of students for future professional activities during their studying at a high educational institution.

The integration of different types of educational institutions, levels of professional education, a professional education content, organizational and administrative process makes the effectiveness, structural and functional 
stability of this integrated system.

The integrated educational-industrial complex will operate efficiently if coordinated links of key subjects of the integrated system "college-university-production" will be activated. A set of coordinated activities of educational institutions of professional education and enterprises helps:

- Constant contact of educational institutions with the labor market in order to monitor its requirements and changes;

- Consideration of industry demands in the development of curricula; continuous updating of knowledge and skills of professionals due to their obsolescence;

- Professionalization of education; reduction of specialties within multidisciplinary training;

- Success rate evaluation of the academic programs that prepare graduates for future life; periodic research of graduates' careers (whether experience received in a college is sufficient for the profession acquirement); use of the results for evaluation and adjustment programs;

- Developing partnership links "college — university—enterprise" including: organization of training at a plant; contribution of enterprises in the modernization of training equipment; participation of professionals in the learning process;

- Development of joint training programs by universities and companies (interaction at the stage of organizing the learning process);

- Training at a plant (internships);

- Participation of industry professionals in the management of vocational education institutions;

- Establishment of professional consultative commissions, developing a curriculum content in various specialties, which include representatives of industry, educational institutions, government education authorities, local authorities, enterprises employees;

- Various forms of employment promotion: internship search by universities; distribution; universities employment services help; databases containing information about undergraduate and graduate students' job preferences and providing this information to interested organizations; educational institutions guarantee for work to its graduates and etc. (Mukhametzyanova \& Shaidullina, 2011; Zhurakovsky \& Sazonova, 2010).

\section{Methodological Framework}

The methodology of this problem study is based on the integrative approach that creates conditions for continuous interaction of elements not only internally, but also with the environment. The productive sign of integration is not the links density, but the integrative unity of its components. The necessary condition for the development of the integrated system "college - university - enterprise" is a functionally stable relation between vocational training institutions and structures of the sectorial production.

Integration processes in the system of a continuous vocational education, caused by modern necessity and addressed to collective decision of education and industry common problems, are not mechanistic and artificial, but result from historical and economic development of this system.

Natural interpenetration of functions of integrated system "college — university—enterprise" subjects creates a more dynamic and effectiveness of integration processes by eliminating the constraints factors on the organizational and structural, content and technological levels that provides structural and functional resistance to the integration process. The major structure forming element of the internal structure of the integrated system is the person possessing the purposefulness of behavior and tending to one's own "self completing" through integrative links with the external environment, where the competitive properties, as a specific system properties, can not only self complete, but also to transfer the whole system to a new level.

\section{Results}

\subsection{Coordinating Function}

The main function of the integrated educational-industrial complex is a coordinating function, aimed at the agreed interaction of social infrastructure, customers and employers in the region, taking into account the specifics of the region and the interests of the educational process subjects, as well as the transition from traditional hard-regulated forms of management to the level of co-management and self-management, that is, reflexive management. 


\subsection{Prognostic Function}

For the survival of mankind, its transition to sustainable development it is important to use forward-looking mechanisms, mechanisms of foresight and forecasting. An innovative shift from unsustainable to sustainable development is required, it is important to include in the educational process the existing and possible forms and mechanisms of innovation-information model of the educational process, where instead of memorization learning comes the forward-looking modeling, based on the principles of a more creative, developing education (Smirnov and Tkachenko, 2004). Therefore, in the present conditions of innovative development of engineering and technologies as a necessary feature of the integrated educational-industrial complex we distinguish a prognostic function oriented to update the philosophy of technical education in connection with a new social order, defining new requirements for its structure, content, quality, focused on improving the students professional training, raising a competitive personality, ready to continuous updating one's knowledge. This function also implies realistic forecast of development parameters of the integrated system "college-university-production", a good example of it is the assessment of the upcoming reduction of the university applicants number due to demographic decline, which requires a search for alternative sources of students number maintenance and sources of budget replenishment. One of these sources there can be the integrated system "college - university-production".

\subsection{Anticipatory Function}

An anticipatory function supposes collective solutions of educational and industrial problems, promoting forward-looking practice with the use of innovative equipment for getting a qualitatively new knowledge and forecasting the dynamics of the scientific and technical world view, it is realized through the implementation of educational activities in the integrated system "college-university-production", new forms, methods, innovative techniques, advanced management methods of integrated system, interaction with customers and producing departments. The general innovative structure of the integrated system "college-university-production" can be represented in the form of three components, each of them is determined by inherent factors and puts forward its demands to change well-established traditional approaches:

- Educational innovations, which are determined by such factors as new educational programs, training techniques, teaching staff qualification, which require solving problems related to the need: combining innovative and regulatory plans; retraining and professional development of teachers in the field of innovation; the development of new learning and methodic materials that reflect the latest achievements in the studied areas of knowledge and new training techniques; combining different pedagogical views on the methods of training and education of students; change control circuit of the educational process to such an extent when the potential of pedagogical and research teams of vocational education institutions in the innovation process are fully realized;

- Scientific and technical innovations, which are determined by such factors as scientific and technical potential of integrated educational-industrial complex, financial support, information support, scientific and technical infrastructure, that set the requirements for modern experimental and laboratory facilities formation; creation a portfolio of orders to perform applied research in the framework of $\mathrm{R} \& \mathrm{D}$, they are ordered by organizations and industrial enterprises of all forms of ownership; search for alternative sources of funding, the total amount of which shall ensure the effective implementation of innovative processes; defining the conditions for inclusion students in the research activities at all levels, including the R \& D and testing of prototypes stages;

- Social and managerial innovations, which are determined by such factors as a management system of innovative activities, a legal relations system of innovative activities subjects, a motivation system and personnel.

The anticipatory function is provided also through the creation of state scientific and educational innovative corporations on the basis of higher vocational education institutions and state research organizations with developed infrastructure, able to integrate and coordinate activities of formed, with their participation, joint research laboratories, regional centers of technologies transfer, small consulting and promotional companies will provide the necessary basic elements of the national innovative system, stimulate the flow of capital in science and education, to orient the preparation and training of technical specialists based on the needs of industrial enterprises. The anticipatory function also involves ensuring innovative development of the integrated system "college - university - production" implemented through a collective decision of educational and industrial problems, promoting forward-looking practice with the use of innovative equipment for a qualitatively new knowledge and forecast the dynamics of the scientific and technical world view. 


\subsection{Consolidating Function}

The decision of modern global problems requires long-term science-intensive projects that demand the participation of a numerous team of researchers, that indicates the need to form a special ethics of relationship, including special communication skills, which allow working in conditions of mutual trust and cooperation, excluding any conflict situations and moments of misunderstanding each other.

The team consists of different individuals who exhibit complementary skills and abilities, abilities to group activities, to cooperation with other employees, a readiness to assume responsibility for the results of one's labor, environment and other true values. Therefore, it is very important to be able to use every opportunity of someone's support and cooperation. A. Einstein, who said: "We cannot solve our problems with the same level of thinking that created them." The whole in such situations is often greater than the sum of items, and do not ignore alternative ways of different perception of reality, as members of the team can achieve such things that individuals cannot. In this regard, one of the main functions of the integrated educational-industrial complex is a consolidating function supposing team cohesion of the integrated system "college - university - production" and production the ability to maintain its integrity as an independent association of people. In the literature there is a scientific justification for the assumptions that the "the cohesion is an important social and psychological function of management." The cohesion depends on the extent, to which the collective psychological centripetal "force" is expressed, that connects and holds them together. That is why a slight conflict, a failure at work, discontent of working conditions lead to collapse of a group. Meanwhile, the cohesive social group consolidates more at failures and difficulties, destabilizing shocks are not so dangerous for it. Therefore, it is able to solve together complex and difficult tasks (Mukhametzyanova \& Pugacheva, 2007).

\subsection{Corporate Function}

The integrated educational-industrial complex performs a corporate function, supposing a union of efforts and actions of the integrated system "college - university - production" subjects, aimed at consolidating their interests to maintain competitiveness and integrity as an independent association.

The first common feature of corporatism is a stability of the group, its external manifestation is a time index. The second feature of corporatism is a positive attitude to participation in a particular collective activity. The third feature is a mobilization base (a strong personality, a common interest, a functional complementarity). The fourth feature is the organizational constraints (regulations and conditions of their functioning).

The corporatism occurs, strengthens, acquires stability and social status, and, finally, becomes the corporation participants' means (or the tool) of their effective interaction.

It is possible to give the following definition of corporatism: a modern corporatism is a set of rational principles of human interaction that characterizes their organization by the effectiveness of their complementarity, leading them (people) to the feeling of comfort, security and expanding opportunities.

For the education system there is the following condition of "corporatism" effectiveness-flexible means of responding to changes in science and technology and the introduction of necessary elements into an educational content in order to correspond training of future specialists to a work in the changed circumstances.

It should be noted that the institutions of vocational education today give their graduates a fundamental education, but not always have highly qualified personnel in a specific field able to give them practical skills for fast, full inclusion in the work of the enterprise. It is possible to bridge this gap by developing a system of corporate education at the expense of educational services "customer", with the assistance of its manufacturing base and specialists. Thus, a cluster policy, aimed at the integration of education and production, plays an important role in the development of corporate education.

\subsection{Sublimating Function}

The integrated educational-industrial complex is the ground where joint coordinated efforts of all subjects of the integrated system "college - university — production" should be directed to make their heritage and the tool of each survivance from their achievements, helping and complementing each other's efforts. It is the synergy of these joint actions that will help to increase in the future the power of each and turn the constant search for ways to survive into an inexhaustible source of intellectual capital increasing. However, the achieving of any real results depends on a number of the following factors:

- In the coming years those states will prosper that provide the most complete manifestation of the professional skills and talents of their citizens, be able to excel in the acquisition of new knowledge and practical achievements transforming them into the most advanced technologies and products; 
- The innovative system will function effectively only on the basis of science-intensive high-tech industries (manufacturing), i.e. these are "industries, spheres or types of economic activities that result in the products (goods, works, services) with a significant added value obtained through the application of science and technology development, characterized by a high share of domestic expenditure on research and development in the value of production of such products ";

- It requires a single union of science, education and industry able to make innovative breakthroughs (Shits and Medvedev, 2004);

- It is necessary such a development of industry and business which will require the results of basic scientific research and a highly educated labor force (Shudegov, 2006).

Such a possibility is the transition of business and industry to the innovative way of development which can only be achieved with the active use of deep integration potential of the national science, institutions of secondary and higher vocational education with production. In this regard, we consider the allocation of a sublimating function lying in the usage of mechanisms of some integration system subjects in order to achieve the purpose of others, for which independent achievement of this goal was unattainable. However, it should be noted that the achievement of the objectives should not be at the expense of each other, but for the benefit of each other.

\section{Discussions}

Previous studies have examined various problems of integration in education, in particular: issues of continuing professional education (Vladislavlev, 1989; Mukhametzyanova, 2005; Novikov, 2005, etc.); the integration of school, high school and industry (Chudov, 2004; Shaidullina, 2009, etc.); integration of education, science and manufacture (Mukhametzyanova, 2005; Sazonova, Sidyakina, \& Ishchenko, 2010, etc.); integration of education and industry (Smirnov, 2001; Tkachenko, 2004, etc.); the inter-subject integration of pedagogical knowledge (Bezrukova, 1994; Zagvyazinsky, 1990); the integrated management of the secondary and professional education (Berulava, 1990; Ibragimov, 2011; Fedotova, 1995), and other.

However, the analysis of scientific and pedagogical literature on research issue and relevant experience of practice leads to the conclusion that there have not been considered the functions of development of integrated educational-industrial complex "college — university—enterprise."

\section{Conclusion}

The structural and functional stability of these subjects' integration in regional system of professional education is achieved through the creation of the common educational-industrial complex which functions are defined as follows:

- Coordinating, aimed at the agreed interaction of social infrastructure, customers and employers in the region, taking into account the specifics of the region and the interests of the educational process subjects, as well as the transition from traditional hard-regulated forms of management to the level of co-management and self-management.

- Prognostic, oriented to update the philosophy of technical education in connection with a new social order defining new requirements for its structure, content, quality, focused on improving the students' professional training, raising a competitive personality ready for continuous updating one's knowledge.

- Corporate, supposing a union of efforts and actions of the integrated system "college—university—production" subjects, aimed at consolidating their interests to maintain competitiveness and integrity as an independent association;

- Consolidating, supposing a team cohesion of the integrated system "college — university—production" and production the ability to maintain its integrity as an independent association of people;

- Anticipatory, supposing collective solutions of educational and industrial problems, promoting forward-looking practice with the use of innovative equipment for getting a qualitatively new knowledge and forecasting the dynamics of the scientific and technical world view;

- Sublimating, lying in the usage of mechanisms of some integration system subjects in order to achieve the purpose of others, for which independent achievement of this goal was unattainable.

\section{References}

Berulava, M. N. (1990). Integration of general and vocational education. Soviet pedagogy, 9, 57-60.

Bezrukova, V. S. (1994). Integration processes in teaching theory and practice (p. 152). Ekaterinburg. 
Chudov, V. L. (2004). System integration of the Lyceum, the university and production for sustainable development of quality educational training (p. 192). Software Radio Press.

Fedotova, L. D. (1995). Didactic principles of forming an integrated content of initial vocational training (p. 112). Moscow.

Ibragimov, G. I. (2011). Innovative learning technologies in the conditions of implementation of competence-based approach. Innovations in Education, 4, 4-15.

Masalimova, A. R., \& Shaidullina, A. R. (2006). Foreign experience of integration of research, teaching and practice of students of higher technical school. Kazan Pedagogical Journal, 5(47), 54-61.

Mukhametzyanova, G. V. (2005). Professional education: Problems of quality and academic support (p. 319). Magarif Press.

Mukhametzyanova, G. V., \& Pugacheva, N. B. (2007). The cluster approach to the management of vocational education (p. 144). Kazan.

Mukhametzyanova, G. V., \& Shaidullina, A. R. (2011). Regional Integration Processes in the Vocational Education System (1st ed., p. 232). Idel Press.

Novikov, A. M. (2005). Development of national education: Polemical reflections (p. 176). Egves Press.

Sazonova, Z. S., Sidyakina, N. Y., \& Ishchenko, V. V. (2010). Training managers of high technology: Student-approach. Higher Education in Russia, 4, 27-35.

Shaidullina, A. R. (2009). Principles of integration ssuz-university-production in terms of continuing professional education. Higher Education in Russia, 5, 140-144.

Shaidullina, A. R., Krylov, D. A., Sadovaya, V. V., Yunusova, G. R., Glebov, S. O., Masalimova, A. R., \& Korshunova, I. V. (2015). Model of Vocational School, High School and Manufacture Integration in the Regional System of Professional Education. Review of European Studies, 7(1), 63-67.

Shaidullina, A. R., Masalimova, A. R., Vlasova, V. K., Lisitzina, T. B., Korzhanova, A. A., \& Tzekhanovich, O. M. (2014). Education, science and manufacture integration models features in continuous professional education system. Life Science Journal, 11(8s), 478-485.

Shits, M., \& Medvedev, Y. (2004). In Union of Education and Science, Russian born Newton and Plato. $\begin{array}{lllll}\text { Rossiyskaya Gazeta. } & \text { Retrieved } & \text { March } & \text { 12, 2004, }\end{array}$ http://informika.ru/text/magaz/newpaper/messedu/2004/cour0403/3500.htm

Shudegov, V. E. (2006). Integration of science, education, business and industry: Innovation and investment aspects. International scientific conference. Retrieved April 17, 2006, from http://www.sciencerf.ru/client/doctrine.aspx?ob_no=2580\&cat_ob_no $=244$

Smirnov, I. P., \& Tkachenko, E. V. (2004). Social Partnership: What will happen with employers? (Results of a pilot study of the All-Russian Social) (p. 32). Moscow: "Aspect".

Smirnov, I. P., \& Tkachenko, E. V. (2004). Social partnership: What awaits employers? Results of the pilot the All-Russian social studies. Aspect Press, 32.

Tkachenko, E. V. (2001). Basics regionalization basic vocational education (p. 42). Centre APO Press.

Ursul, A. (2008). Principle of temporal integrity and education. Herald of high school, 3, 28-35.

Vladislavlev, A. P. (1989). In search of the concept. Bulletin of high school, 6, 48-51.

Zagvyazinsky, V. I. (1990). Indirect impact on the methodology of practice. Soviet pedagogy, 3, 65-67.

Zhurakovsky, V. M., \& Sazonova, Z. S. (2010). Actual problems of modernization of vocational education. Higher education in Russia, 5, 4-12.

\section{Copyrights}

Copyright for this article is retained by the author(s), with first publication rights granted to the journal. This is an open-access article distributed under the terms and conditions of the Creative Commons Attribution license (http://creativecommons.org/licenses/by/3.0/). 